\title{
Experimental analysis of system parameters for minimum cutting fluid consumption when machining Ti-6Al-4V using a novel supply system
}

\author{
Salah Gariani $^{1} \cdot$ Islam Shyha $^{1,2} \cdot$ Fawad Inam $^{1} \cdot$ Dehong Huo $^{3}$
}

Received: 3 July 2017 / Accepted: 13 October 2017 /Published online: 29 November 2017

(C) The Author(s) 2017. This article is an open access publication

\begin{abstract}
This paper presents the development of a new controlled cutting fluid impinging supply system (Cut-list) to deliver an accurate quantity of cutting fluid into machining zones through precisely oriented coherent round nozzles. The performance of the new system was evaluated against a conventional system during the step shoulder milling of Ti-6Al-4V using a water-miscible vegetable oil-based cutting fluid, which was phase 1 in this comprehensive study. The use of Cut-list resulted in a significant reduction up to $42 \%$ in cutting fluid consumption as well as reductions in cutting force, tool flank wear, average surface roughness $\left(R_{a}\right)$ and burr height (Gariani et al. in Appl Sci 7(6):560, 2017). This paper details phase 2 of the study which was aimed to investigate the effects of working conditions, nozzle positions/angles and impinging distances on key process measures including cutting forces, workpiece temperature, tool wear, burr formation and average surface roughness of the machined surface. Feed rate showed a significant effect on mean
\end{abstract}

Islam Shyha

islam.shyha@northumbria.ac.uk

Salah Gariani

salah.gariani@northumbria.ac.uk

Fawad Inam

fawad.inam@northumbria.ac.uk

Dehong Huo

dehong.huo@newcastle.ac.uk

1 Department of Mechanical and Construction Engineering, Faculty of Engineering and Environment, Northumbria University at Newcastle, Newcastle Upon Tyne NE1 8ST, UK

2 Production Engineering Department, Faculty of Engineering, Alexandria University, Alexandria 21544, Egypt

3 School of Mechanical and Systems Engineering, Newcastle University, Newcastle Upon Tyne NE7 7QH, UK values of cutting force, burr formation and surface roughness, whereas average workpiece temperature and flank wear values are very sensitive to cutting speed. Nozzle position at a $15^{\circ}$ angle in the feed direction and $45^{\circ} / 60^{\circ}$ against feed direction assisted in minimising workpiece temperature. An impinging distance of $55 / 75 \mathrm{~mm}$ is also necessary to control burr formation, workpiece temperature and average surface roughness. It can be concluded that Cut-list gave promising results compared to conventional flood cooling systems in terms of the evaluated machining outputs. Therefore, the new system can be considered as a feasible, efficient and ecologically beneficial solution, giving less fluid consumption in machining processes.

Keywords Fluid consumption - Coherent nozzle, vegetable oil-based $\cdot$ Cutting fluid $\cdot$ Shoulder milling $\cdot$ Ti-6Al-4V

\section{Introduction}

Historically, manufacturing by machining has prospered from the use of cutting fluids. Cutting fluids are supplied to the machining zone in order to improve machining performance. Cooling and lubrication are the key functions of cutting fluids. Additionally, they transport chips away from the machining zone, minimise the built-up edge (BUE) and protect machined components and machine tool parts from corrosion [1, 2]. It is reported that the costs related to cutting fluids are approximately $16.9 \%$ of the total manufacturing costs, compared to tooling costs which represent about $7.5 \%$ [3]. This cost can be increased to up to $30 \%$ for machining refractory materials such as titanium and nickel-based alloys [4]. It is also estimated that the annual consumption of cutting fluids is about 100 million gallons in the USA [5]. A more effective cutting fluid supply method will significantly contribute to reducing fluid consumption and improving cutting performance. Currently, 
conventional flood cooling is the most common method used on machine shop floors, in which a large quantity of cutting fluid (e.g. up to $225 \mathrm{l} / \mathrm{min}$ for multiple teeth tool cutters) is continuously supplied into the machining zone [6]. However, high fluid consumption and low penetration ability, particularly at high cutting speeds, are the main disadvantages of this technique [7, 8]. High fluid consumption results in increasing disposal and maintenance costs, particularly when mineral/ petroleum oil-based fluids are used. These types of fluids are claimed to cause human and environmental hazards due to their high content of toxic elements such as chemical agents, hydrocarbons and extreme pressure (EP) additives $[9,10]$. Between 13 and $32 \%$ of cutting fluids used in the EU and USA are disposed of without treatment [11]. Thus, additional processing for fluid waste (e.g. oil/water separation, ultrafiltration, conditioning and incineration) prior to disposal is always required $[5,10]$. In order to address these issues, minimum quantity lubrication (MQL) and minimum quantity cooling lubrication (MQCL) have been introduced to minimise fluid consumption in the machining operations. Fluid is atomised by missing with compressed air and is supplied as an aerosol. The cutting fluid in MQL and MQCL reaches the tool-workpiece interface through capillarity forms a film at the interface. This helps in lubrication and reducing contact pressure. Good penetrability of MQL and MQCL was also assisted to minimise cutting temperature in machining zone (particularly MQCL owing to its variant properties such as cooling compared to MQL), resulting in a reduction of tool wear and built-up edge formation. Improved surface integrity and desirable chip shape were also obtained when MQL and MQCL are used compared to dry and conventional flood cooling conditions [12-15]. Although MQL and MQCL are often used with biodegradable lubricants, resulting fumes by these systems particularly at higher cutting speeds is the main limitation [16]. High-pressure cooling (HPC), cryogenic cooling, oil/water mist and compressed air/gas/vapour supply systems have also been employed as alternative methods instead of conventional flood cooling supply systems to reduce fluid consumption and mitigate the hazards of using mineral oil-based fluids $[17,18]$. However, the high cost of the consumables involved (e.g. liquid nitrogen and gases), pumping and micro-particle filtration equipment are substantial limitations [19-23]. Additionally, the inaccurate estimation of cutting fluid flow rates during machining operations is also a clear disadvantage.

In the same vein, vegetable oil (VO)-based cutting fluids have been introduced as potential alternatives to conventional fluid counterparts due to their high biodegradability (i.e. $100 \%$ within 28 days) [24] and superior physical and chemical properties $[25,26]$. The homogeneity and super-density of vegetable oil molecules can also help to form a thick, durable and strong film layer that affords VOs the ability to withstand high contact pressure [27, 28]. Vegetable oil-based stocks have a high kinematic viscosity (e.g. $40.05 \mathrm{cSt}$ at $40^{\circ} \mathrm{C}$ for sunflower oil) and high heat conductivity of up to $0.17 \mathrm{~W} / \mathrm{m}$.K compared to $20.06 \mathrm{cSt}$ at $40{ }^{\circ} \mathrm{C}$ and $0.12 \mathrm{~W} / \mathrm{m} \mathrm{K}$ for mineral oil-based fluids $[29,30]$. Thus, it is estimated that the global demand for biodegradable fluids is expected to increase by around $58 \%$ or 0.3 million tonnes in 2018 compared to 2011 [17].

Nozzle placement plays a crucial role, particularly in supply methods using less fluid consumption (e.g. MQL and oil/water mist). The impact of nozzle position on the turning of the AISI 1045 at an angle of $20^{\circ}$ and $50^{\circ}$ has been investigated [31] using MQL with palm oils and water/mist. Tests were performed at a cutting speed of $125 \mathrm{~m} / \mathrm{min}$, feed rate of $0.2 \mathrm{~mm} / \mathrm{rev}$ and $0.2 \mathrm{~mm}$ depth of cut and $1000 \mathrm{~mm}$ cutting length. The results showed that nozzle placement at $20^{\circ}$ produced lower tool flank wear of 63 and $71 \mu \mathrm{m}$ for MQL and water/mist cooling, respectively, compared with 71 and $85 \mu \mathrm{m}$ when a $50^{\circ}$ angle was employed. In another study [32], nozzles positioned at $45^{\circ}$ with respect to feed direction resulted in the best lubrication for the upmilling and downmilling of Inconel 182 using MQL (Fig. 1). The influence of nozzle position has also been evaluated when grinding 100Cr6 hardened steel using an MQL application [33]. It was found that MQL oil mist effectively penetrated into the boundary layer flow around the grinding wheel when the nozzle was positioned toward the wheel at an angle of $10^{\circ} / 20^{\circ}$ to the workpiece surface.

Additionally, titanium alloys are very attractive materials, particularly for aerospace and automotive applications, due to their superior inherent physical and mechanical properties (e.g. $\sim 50 \%$ density of steel, high strength, high operational temperatures and exceptional corrosion resistance). Ti-6Al$4 \mathrm{~V}$ is the most widely used titanium alloy which is currently used in a wide range of engineering sectors including aerospace, automotive, medical, military aviation and sports equipment. It features relatively higher mechanical properties (i.e. high strength, low weight ratio and excellent corrosion resistance). However, Ti-6Al-4V has low machinability index compared to other metallic alloys such as steels owing to its low thermal conductivity $(7.2 \mathrm{~W} / \mathrm{m} . \mathrm{K}$ for annealed Ti-6Al$4 \mathrm{~V})$ and high dynamic shear strength. This generates a large quantity of heat close to the machining zone, which leads to the use of relatively lower cutting speeds (i.e. $30-90 \mathrm{~m} / \mathrm{min}$ ) to remain economical $[34,35]$ as well as has a knock on effect on cutting tool life. Additionally, the low E modulus of titanium alloys ( $\sim 110 \mathrm{GPa}$ for annealed Ti-6Al-4V) promotes tool rubbing, chatter and product geometry issues and contributes to higher tool wear rates $[36,37]$. On the other hand, increasing machining speed when cutting Ti-6Al-4V alloy with less manufacturing cost (e.g. using minimum amount of cutting fluid) is deemed necessary for process improvement. These reasons encouraged the authors to use Ti- $6 \mathrm{Al}-4 \mathrm{~V}$ as the workpiece material to examine the novel cutting fluid supply system. In the same vein, vibration is more prone to occur in 
Fig. 1 MQL traditional nozzle positions. a Against feed direction in downmilling. b With feed direction in upmilling. $\mathbf{c}$ With feed direction in downmilling. $\mathbf{d}$ Against feed direction in upmilling [32]

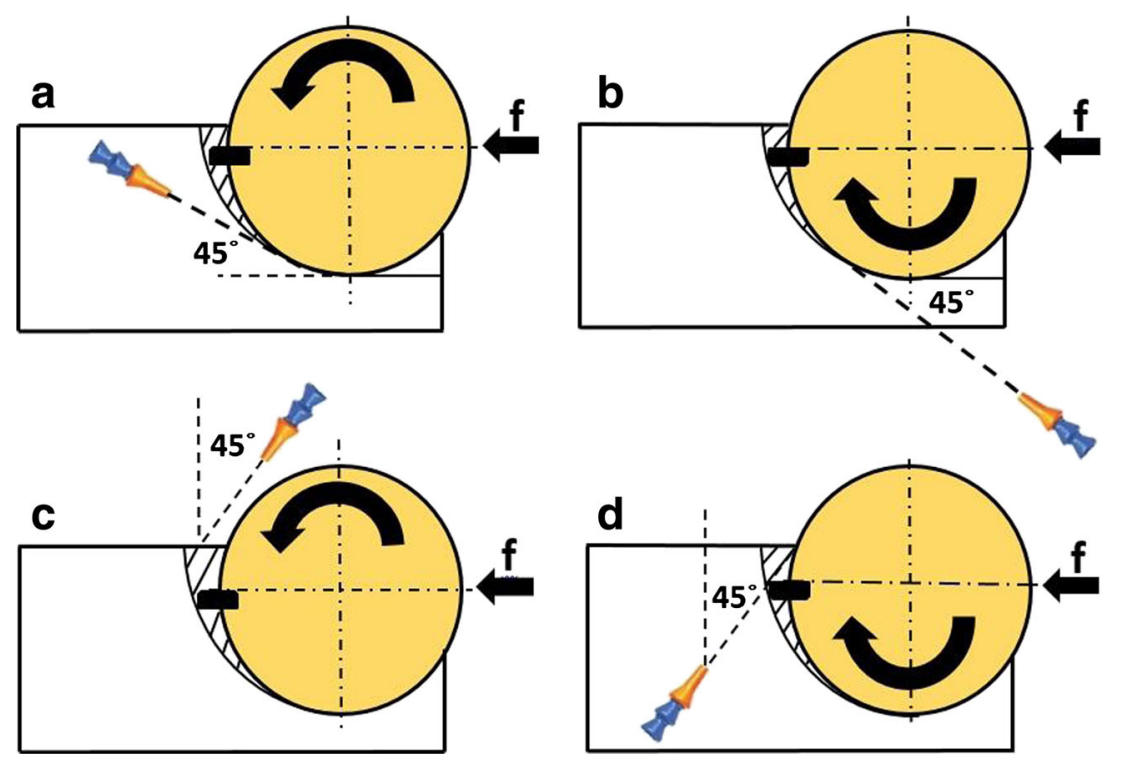

milling titanium due to self-excited vibrations (i.e. chatter) between the workpiece and cutting tool (owing to its low E modulus) [38]. Localised shearing, which is correlated to the generation of cyclic force, is responsible for self-exited vibration. This vibration induces waviness of the surface in the first cut. In the following cut, the tool cuts into the wavy surface and generates a further variation of chip geometry/thickness and force that excites the structure, providing greater vibration between the workpiece and cutter, resulting in wave regeneration phenomenon [35, 39]. Thus, rigid clamping is essential for avoiding effect of low E modulus of titanium alloys particularly for chatter-free surfaces [40]. Additionally, cutting tool path (i.e. contouring and ramping) and the inclined surfaces (e.g. concave and convex) can also affect cutting force, tool and workpiece deflection when milling titanium. It was revealed that the cutting force and tool deflection in contouring tool path style were found to be lower than that of ramping tool path mode. This was explained by the outcome that the contouring tool path style offers movements parallel to the inclined surface from the axis and ideal to move the chips away. In addition, the cutting forces obtained in the machining of convex inclined surfaces are found smaller in comparison to that obtained in the machining of concave inclined surfaces. This is because the chip was comfortably removed from the machining zone in the convex inclined surface. Furthermore, the cutting tool works on the inner surface and comes in contact with the workpiece with a longer cutting edge, resulting in increases in the cutting force and tool deflection values [41]. In a similar vein, it was indicated that cutting forces are strongly affected by the surface inclination angle $(\alpha)$ in milling operations. Influence of surface inclination angle on cutting forces was lower in the case of $\alpha \geq 15$, whilst the highest impact of inclination angle on cutting forces was found with the $\alpha=0^{\circ}$ [42].

Additionally, increasing the machining speed of titanium components is necessary for process improvement. Currently, a parallel machining strategy has been presented in order to extend metal cutting capacity and to minimise chatter. Also, parallel machining involves less bending force applied to the work part, affording additional improvements in product accuracy [43]. In the absence of coolant, titanium alloys are more disposed to react with atmospheric gases and cutting tool material at elevated temperatures, resulting in the degradation of machined surface quality as well as rapid tool wear [36]. Traditionally, using copious amounts of cutting fluid helps when machining titanium and is a dominant 'machining culture' on machine shop floors [44, 45]. Thus, more attention is deemed necessary to reduce fluid consumption during machining titanium alloys, with a particular emphasis on the use of environmentally friendly cutting fluids.

In this work, a novel controlled cutting fluid impinging supply system (Cut-list) is developed and applied to the shoulder milling of Ti-6Al-4V to reduce cutting fluid consumption. Key process measures include cutting force, workpiece temperature, tool flank wear, burr formation and surface roughness. The effects of working conditions (cutting speed and feed rate), nozzle position and impinging distances are also assessed employing the new supply system. The originality of the developed supply system depends on synchronisation between the calculated generated heat in the machining zone with an accurate cutting fluid quantity required to minimise its consumption and simultaneously enhance the cutting performance of titanium alloys. Furthermore, the developed system is beneficial to the machine tool industry, making it very viable in terms of the minimum fluid consumption for machining applications without substantial additional costs. 


\section{Experimental work}

Cut-list (Fig. 2) was designed to supply cutting fluid in feed and against feed directions simultaneously. The angled overhead nozzle ring was placed on a vertical spindle head holding two round coherent nozzles for delivering fluid at three different impinging angles of $15^{\circ}, 45^{\circ}$ and $60^{\circ}$ in the feed direction and similar angles against the feed direction as shown in Fig. 3. Cut-list was also developed to align nozzles in the tool-workpiece contact area at any given elevation angle relative to tool axis using an angled mounting wedge together with an adjustable nozzle holder. Additionally, the design of the adjustable nozzle holder allows the nozzle discharge tips to be placed away from the tool-workpiece contact zone at different impinging distances of 35, 55 and $75 \mathrm{~mm}$. A closed loop Gusher vertical type coolant pump (Gusher Pumps Ltd., Wolverhampton, UK) was used to carry the cutting fluid. The pump was placed directly over the cutting fluid tank to minimise pressure drop in the system feed pipes. The output flow rate was controlled using an oval gear digital type flow meter/ regulator (Badger Meter Europa, Neuffen, Germany) located at $300 \mathrm{~mm}$ away from the coolant pump to ensure steady state flow conditions. The fluid pressure was monitored employing an OMEGA DPG digital-type and dual-scale pressure gauges (OMEGA Engineering Ltd., Manchester, UK), which were mounted directly after an in-line type filter (Magnom Corporation Ltd., Warwick, UK) and before the cutting fluid enters the nozzles.

The new system nozzles were designed based on Webster nozzle geometry $[46,47]$ to generate a high-quality coherent jet stream that affords low misting and minimum entrained air within the jet. These features help Cut-list to penetrate cutting fluid into the machining zone effectively. The internal dimensions of the manufactured coherent nozzle are aperture diameter $(d=1.75 \mathrm{~mm})$, thickness $(t=2.5 \mathrm{~mm})$ and an internal diameter of the feed pipe $(D=12 \mathrm{~mm})$ (see Fig. 3). Step shoulder milling was selected as a cutting strategy in evaluating the new supply system, as shown in Fig. 4. During metal cutting, a greater proportion of the energy consumed (i.e. 90 $98 \%$ ) is converted into heat, whereas the remaining energy is retained as elastic energy in the chip [48-53]. In the present work, $90 \%$ of the total cutting power is considered to be converted into heat (i.e. the total heat generated in the primary, secondary and tertiary deformation zones). Equations 1 and 2 were used to calculate the metal removal rate (MRR) and cutting power, respectively. The accurate flow rate of the cutting fluid required to cool the machining zone is then computed according to Eq. 3 [54].

$$
\begin{aligned}
& \mathrm{MRR}=f \cdot Z \cdot N \cdot K_{1} \cdot a_{p} \cdot a_{e} \\
& P_{c}=\frac{U \cdot \mathrm{MRR}}{60} \\
& Q=\frac{U \cdot \mathrm{MRR}}{4.148 \cdot C \cdot \rho \cdot \eta_{\text {nozzle }} \cdot \Delta \theta}
\end{aligned}
$$

where MRR is the metal removal rate $\left(\mathrm{mm}^{3} / \mathrm{min}\right) ; a_{p}$ and $a_{e}$ are the axial and radial depth of cut, respectively (mm); $f$ is the feed rate $(\mathrm{mm} / \mathrm{rev}) ; Z$ is the number of teeth; $N$ is the spindle speed (rpm); $K_{1}$ is a compensation factor for minimising chip thinning $\left(K_{1}=1.96\right)$ [55]; $P_{c}$ is the cutting power $(\mathrm{W})$; $U$ is the specific cutting energy ( $U=4 \mathrm{~W} \mathrm{~s} / \mathrm{mm}^{3}$ for titanium) [56]; $Q$ is the accurate flow rate $(\mathrm{L} / \mathrm{min}) ; \eta_{\text {nozzle }}$ is the coherent nozzle efficiency (0.95) [57]; $\Delta \theta$ is the cutting fluid maximum tolerable temperature increase $\left(\Delta \theta=3{ }^{\circ} \mathrm{C}\right.$ for wet machining)

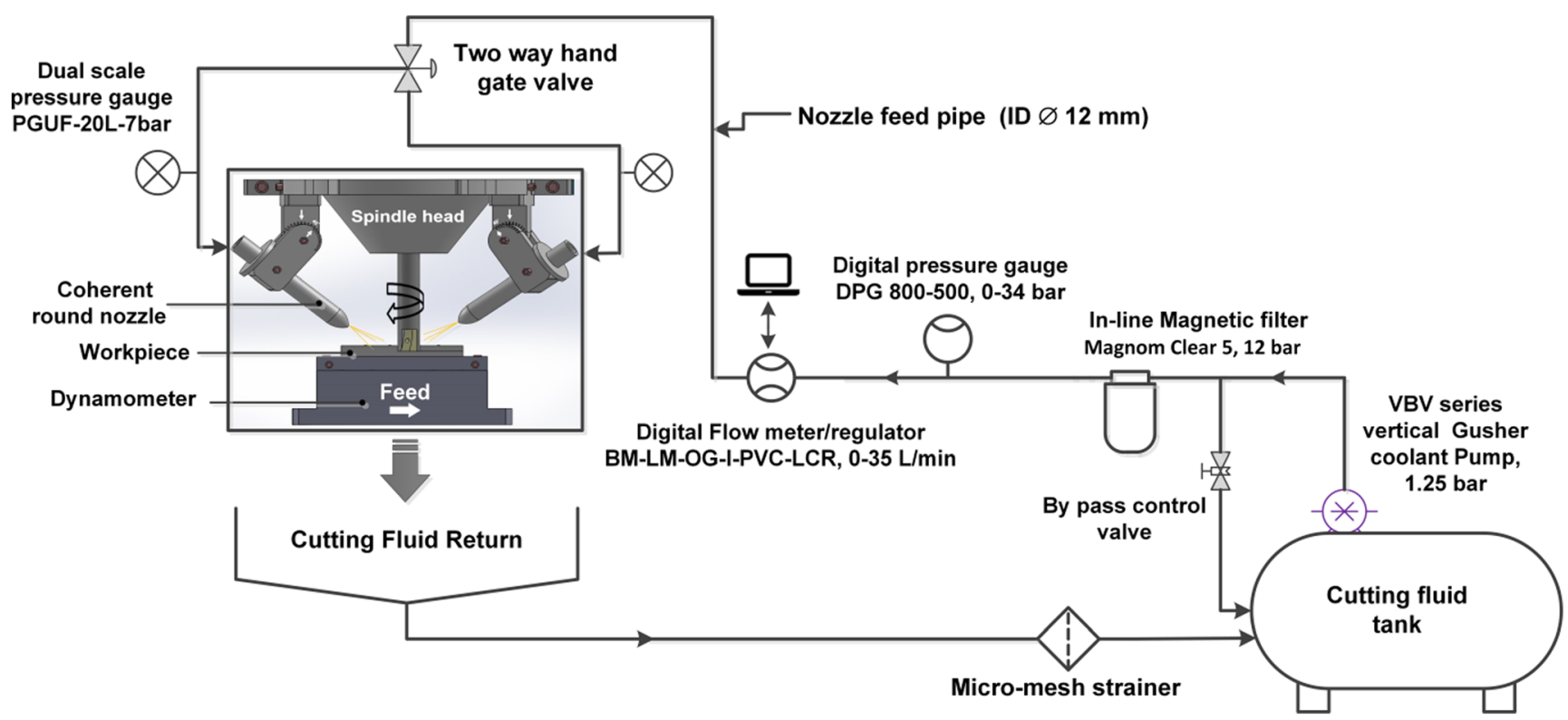

Fig. 2 Schematic view for the new controlled cutting fluid impinging supply system (Cut-list) 
Fig. 3 Detailed view of the new supply system (Cut-list)

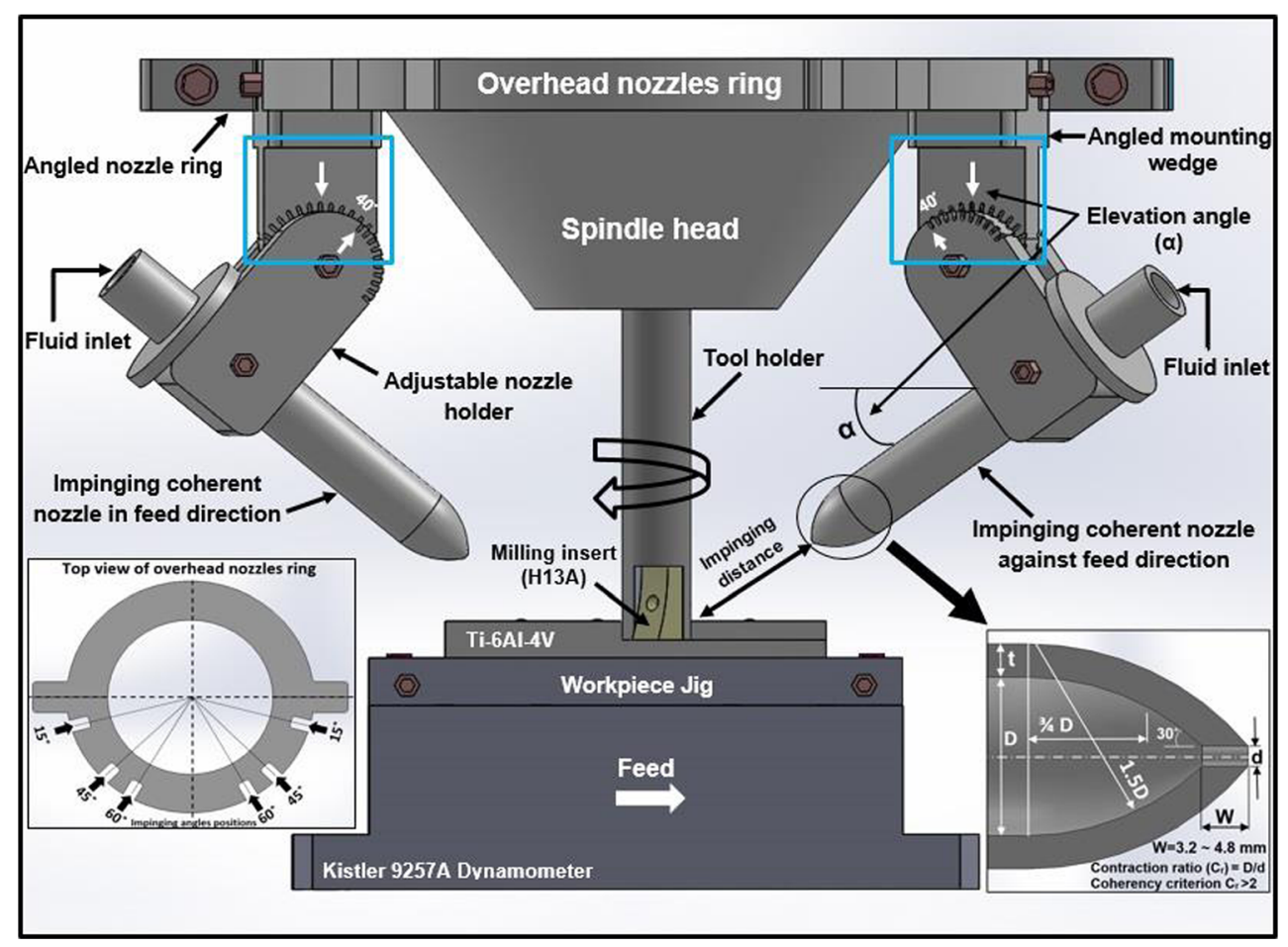

[58]; and $\rho$ and $C$ are the cutting fluid mass density and fluid heat capacity at $10 \%$ concentration $\left(\rho=0.988 \mathrm{~g} / \mathrm{m}^{3}\right.$ and $C=0.948 \mathrm{cal} / \mathrm{g}{ }^{\circ} \mathrm{C}$ ), respectively. Table 1 shows the cutting conditions used for accurate flow rate calculations.

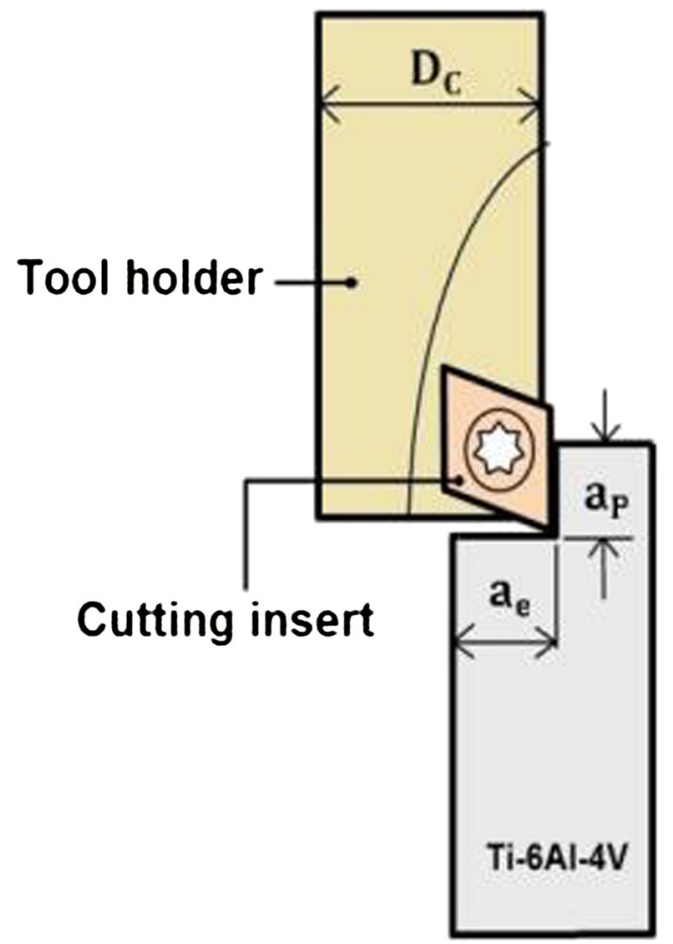

Fig. 4 Schematic illustration of step shoulder milling of Ti-6Al-4V
Additionally, the conventional flood estimations were based on $13 \mathrm{~L} / \mathrm{min}$ per $(\mathrm{kW})$ for cutting titanium as recommended by the Kennametal tool manufacturer [44]. The results showed that the fluid can be supplied at a flow rate of $8 \mathrm{~L} / \mathrm{min}$ per $(\mathrm{kW})$ using Cut-list with a reduction in cutting fluid consumption by up to $42 \%$ compared to the conventional system (see Fig. 5). Cutting fluid velocity and the minimal exit diameter of the round coherent nozzle were determined using Bernoulli's [46] and fluid continuity theories [57], respectively. Table 2 shows the experimental results for all cutting tests.

To fulfil the flow coherency criterion, the contraction ratio (D/d) should be at least $\geq 2: 1$ and the actual nozzle exit diameter $(d)$ must be greater than or equal to the theoretical minimal coherent nozzle exit diameter [57]. To obtain the highest jet stream quality, the actual nozzle exit diameter $(d)$ was fixed at $1.75 \mathrm{~mm}$ for all trials, whereas the contraction ratio was set at $\sim 7: 1$ based on the calculated actual nozzle aperture diameter (i.e. $1.75 \mathrm{~mm}$ ) and nozzle internal feed pipe diameter (i.e. $12 \mathrm{~mm}$ ) which satisfy the above criterion.

Table 1 Cutting conditions and levels used for accurate flow rate computation

\begin{tabular}{ll}
\hline Cutting conditions & Corresponding levels \\
\hline Cutting speed $(\mathrm{m} / \mathrm{min})$ & 95,200 \\
Feed rate $(\mathrm{mm} / \mathrm{rev})$ & $0.1,0.15$ \\
Axial and radial depth of cut $(\mathrm{mm})$ & $5,1.3$ \\
\hline
\end{tabular}


Fig. 5 Flow rate versus cutting conditions and generated heat for the two systems

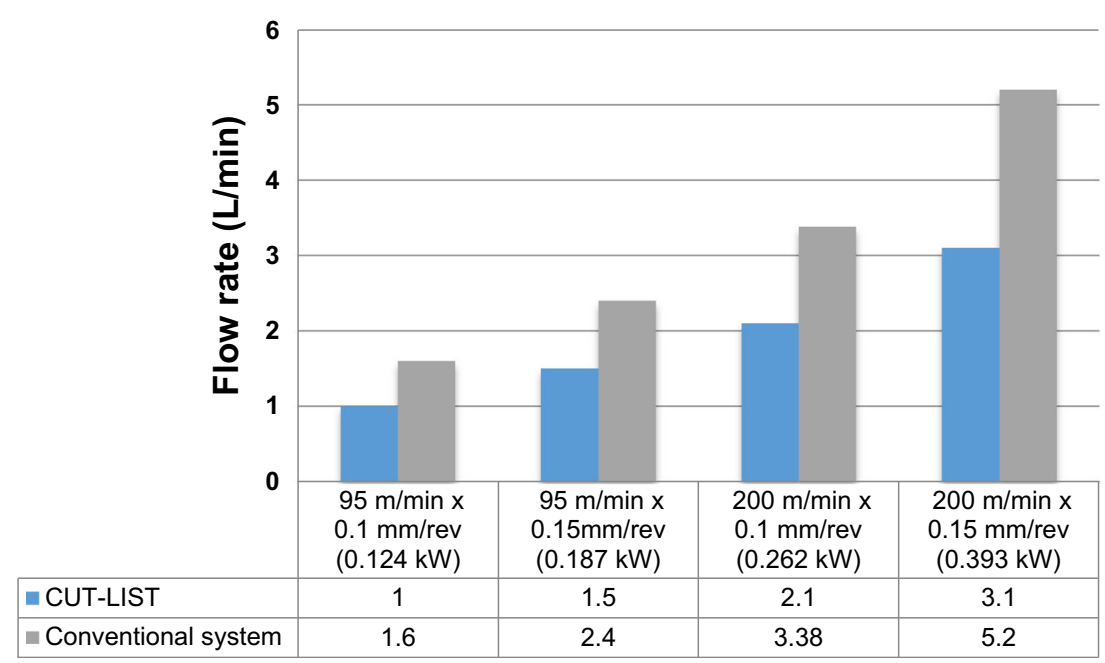

\section{Experimental plan}

The experimental plan was divided into two main parts. Part I evaluated the effect of the settings of the new system on machining output, whereas part II focused mainly on a comparison between the proposed and conventional supply systems. Because the new system has the capability for more settings (i.e. nozzle angles and impinging distance) compared to the existing conventional flood supply system, Cut-list was initially evaluated at three impinging angles in the feed direction, three impinging angles against feed direction and three impinging distances, giving 27 tests at each setting of cutting speed and feed rate (i.e. two levels each). This gives a total of 108 experiments conducted using the new system. Table 3 shows the evaluated factors with their corresponding levels. All trials were carried out using a CNC Cincinnati 750-Sabri vertical milling machine (Cincinnati Machine UK Ltd., Birmingham, UK) with a maximum spindle power of $11 \mathrm{~kW}$. Step shoulder downmilling was performed on annealed Ti-6Al-4V ASTM B 265 grade 5 rectangular blocks, each having a width of $11 \mathrm{~mm}$, height of $25 \mathrm{~mm}$ and length of $103 \mathrm{~mm}$. Each trial involved cutting a length of $103 \mathrm{~mm}$, and a new cutting insert was used to avoid the accumulation of wear from different tests. The axial $\left(a_{p}\right)$ and radial $\left(a_{e}\right)$ depths of cut and nozzle elevation angle $(\alpha)$ of $5 \mathrm{~mm}, 1.3 \mathrm{~mm}$ and $40^{\circ}$, respectively, were maintained for all tests.
Sandvik H13A coarse grain uncoated tungsten carbide inserts with a positive rake angle and a nose radius of $0.8 \mathrm{~mm}$ were used. These inserts were mounted on a $\varnothing 18.5$ (i.e. $\left.D_{c}\right) \times 110$-mm-long square shoulder milling tool holder (Sandvik Coromant, Halesowen, UK), implying a major cutting edge angle $\kappa=90^{\circ}$ with an overhang distance of $60 \mathrm{~mm}$ (i.e. to eliminate chatter). Figure 6 shows the experimental setup using the new Cut-list system.

The single tooth cutter (i.e. $Z=1$ ) was used to facilitate tool wear measurements. A commercial (Vasco1000) watersoluble vegetable oil-based cutting fluid (Jemtech Ltd., East Sussex, UK) containing $45 \%$ pure vegetable oil was used. The fluid was blended at $10 \%$ concentration and regularly checked using a portable refractometer (Cromwell Tools, Luton, UK). Table 4 details the chemical composition and thermo-physical properties of the cutting fluid used throughout the experimentation.

An Alicona Infinite Focus G4 optical microscope (Alicona UK Ltd., Kent, UK) was utilised to capture the average tool flank wear (VB). Average tool flank wear (VB) was measured following each trial in accordance with the ISO 8688-2 (1989) standard. The average surface roughness $\left(R_{a}\right)$ of machined samples was measured using a Taylor Hobson Surtroni 3+ (Taylor Hobson, Leicester, UK). Three $R_{a}$ readings (at the beginning, middle and end of the cut) were recorded, and an average was then computed (see Fig. 7, view A). All $R_{a}$
Table 2 Results of minimal nozzle exit diameters and fluid velocities for Cut-list

\begin{tabular}{llllc}
\hline Cutting conditions & $\begin{array}{l}95 \mathrm{~m} / \mathrm{min} \text { and } \\
0.1 \mathrm{~mm} / \mathrm{rev}\end{array}$ & $\begin{array}{l}95 \mathrm{~m} / \mathrm{min} \text { and } \\
0.15 \mathrm{~mm} / \mathrm{rev}\end{array}$ & $\begin{array}{l}200 \mathrm{~m} / \mathrm{min} \text { and } \\
0.1 \mathrm{~mm} / \mathrm{rev}\end{array}$ & $\begin{array}{l}200 \mathrm{~m} / \mathrm{min} \text { and } \\
0.15 \mathrm{~mm} / \mathrm{rev}\end{array}$ \\
\hline Fluid pressure (bars) & 0.34 & 0.55 & 0.78 & 1.16 \\
Fluid velocity (m/s) & 5.86 & 7.46 & 8.88 & 10.83 \\
$\begin{array}{l}\text { Fluid specific gravity } \\
\begin{array}{c}\text { Minimal nozzle exit } \\
\text { diameter (mm) }\end{array}\end{array}$ & 0.988 & 0.988 & 0.988 & 0.988 \\
$\begin{array}{c}\text { Accurate flow rate } \\
\text { (L/min) }\end{array}$ & 1.42 & 1.50 & 1.62 & 1.75 \\
\hline
\end{tabular}


Table 3 Process variables and their corresponding levels

\begin{tabular}{llll}
\hline Factor & Leve 1 & Level 2 & Level 3 \\
\hline Nozzle angle in feed direction & $15^{\circ}$ & $45^{\circ}$ & $60^{\circ}$ \\
Nozzle angle against feed direction & $15^{\circ}$ & $45^{\circ}$ & $60^{\circ}$ \\
Nozzle impinging distance $(\mathrm{mm})$ & 35 & 55 & 75 \\
Cutting speed $(\mathrm{m} / \mathrm{min})$ & 95 & 200 & \\
Feed rate $(\mathrm{mm} / \mathrm{rev})$ & 0.1 & 0.15 & \\
\hline
\end{tabular}

measurements were conducted in accordance with ISO 4287 and ISO 4288 using a $0.8-\mathrm{mm}$ cutoff and an evaluation length of $4 \mathrm{~mm}$. Top burr height measurements were taken using a digital micro-depth gauge, whilst the burrs images were captured utilising optical microscope (Leica L2). Cutting force signals were collected using a Kistler 9257A dynamometer (Kistler, Winterthur, Switzerland) via a multichannel laboratory charge amplifier. A sample frequency of $2000 \mathrm{~Hz}$ and high-pass filter type with $\left(\mathrm{n}^{64}\right)$ filter order were used to record the cutting force signals. All signals were then analysed utilising Kistler Dynaware software. Workpiece temperature was measured using mineral insulated thermocouple sensors (TEMPCON, West Sussex, UK). A digital four-channel data logger (Onset-HOBO UX120-014M) having sampling rate of 2000 samples/s was utilised for temperature logging. Four Ttype thin sensing probes with $\varnothing 1.0 \mathrm{~mm}$ diameter $\times 10 \mathrm{~mm}$ probe length $\times 2 \mathrm{~m}$ extension cable length were inserted into $\varnothing$ $1.0-\mathrm{mm}$ drilled holes in each sample at $0.5 \mathrm{~mm}$ from the machined surface and $20 \mathrm{~mm}$ apart. A distance of $20 \mathrm{~mm}$ was also allocated before passing over the first thermocouple for ensuring stable steady state thermal conditions (see Fig. 7). Prior to each test, each workpiece material was left for a few seconds to reach ambient temperature $\left(\sim 19^{\circ} \mathrm{C}\right)$. It is worth mentioning that the lowest values of process outputs (i.e. tool wear, $R_{a}$ and burr height) are crucial for the quality
Table 4 Chemical composition/thermo-physical properties of the water-soluble cutting fluid (Vasco1000)

\begin{tabular}{ll}
\hline Composition/property & Corresponding value \\
\hline Mineral oil content & $0 \%$ \\
Oleoyl sarcosine (additives) & $1.0-2.4 \%$ \\
Methylenebismorpholine (additives) & $1.0-4.9 \%$ \\
Zinc alkyl dithiophosphate (additives) & $1.0-4.9 \%$ \\
$\mathrm{pH}$ value & $8.5-9.2$ \\
Mass density $\left(\mathrm{kg} / \mathrm{m}^{3}\right)$ & 988 \\
Dynamic viscosity at $25{ }^{\circ} \mathrm{C}(\mathrm{cP})$ & 1.8 \\
Average heat capacity at at $25{ }^{\circ} \mathrm{C}\left(\mathrm{J} / \mathrm{g} /{ }^{\circ} \mathrm{C}\right)$ & 3.97 \\
\hline
\end{tabular}

improvement of the machined parts and reducing manufacturing costs. For this reason, 'the-lower-the-better' criterion was adopted in this study. For workpiece temperature, surface roughness, burr height and tool wear, three measurements were taken for each test and average was calculated.

\section{Results and discussion}

\subsection{Process analysis and effect of the new system (part I)}

Cutting force Figure 8 shows the effect of process variables on the cutting force. The best settings to minimise cutting forces when shoulder milling Ti-6Al-4V were found to be $95-\mathrm{m} / \mathrm{min}$ cutting speed, $0.1-\mathrm{mm} / \mathrm{rev}$ feed rate and nozzle position at $15^{\circ}$ in the feed direction, $45^{\circ}$ against feed direction and $75-\mathrm{mm}$ impinging distance. Feed rate was found to have a considerable influence on the cutting force over the evaluated range; i.e. cutting forces increased with the increase of feed rate. This is due to the high correlation between cutting force and cutting area (where uncut chip thickness is part of it) and
Fig. 6 Image of experimental setup using (Cut-list)

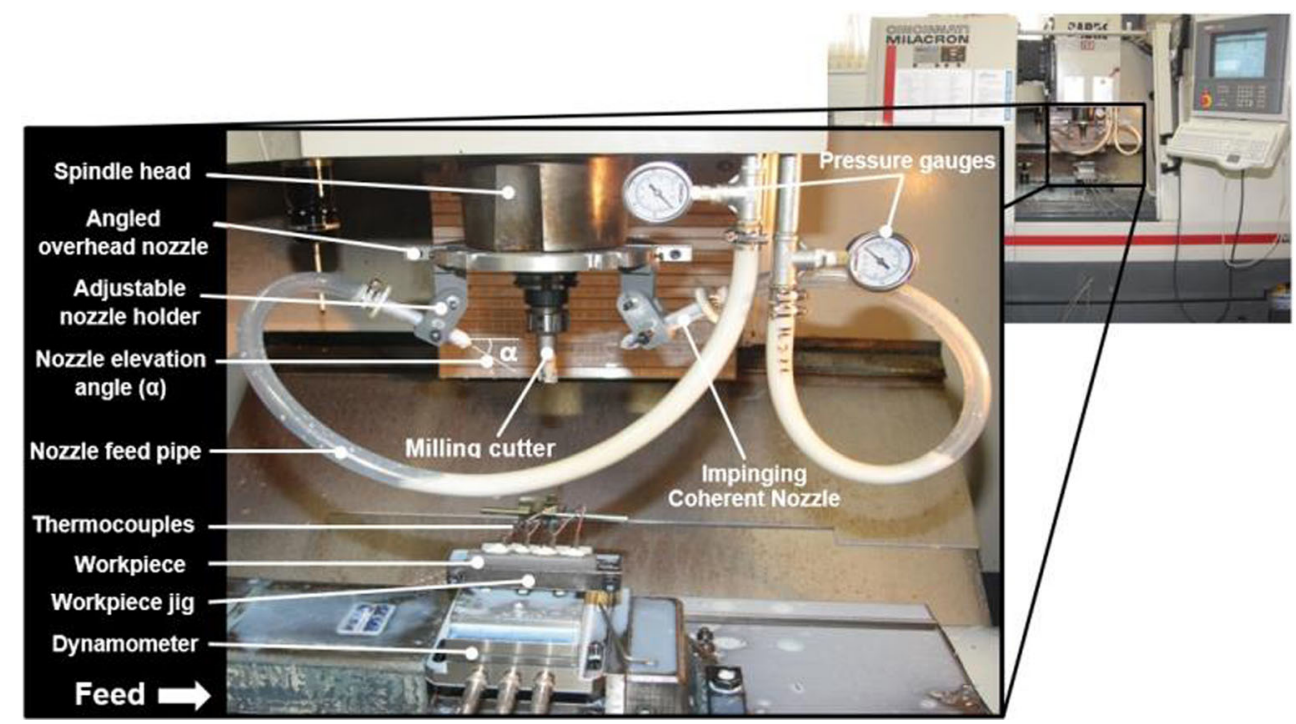




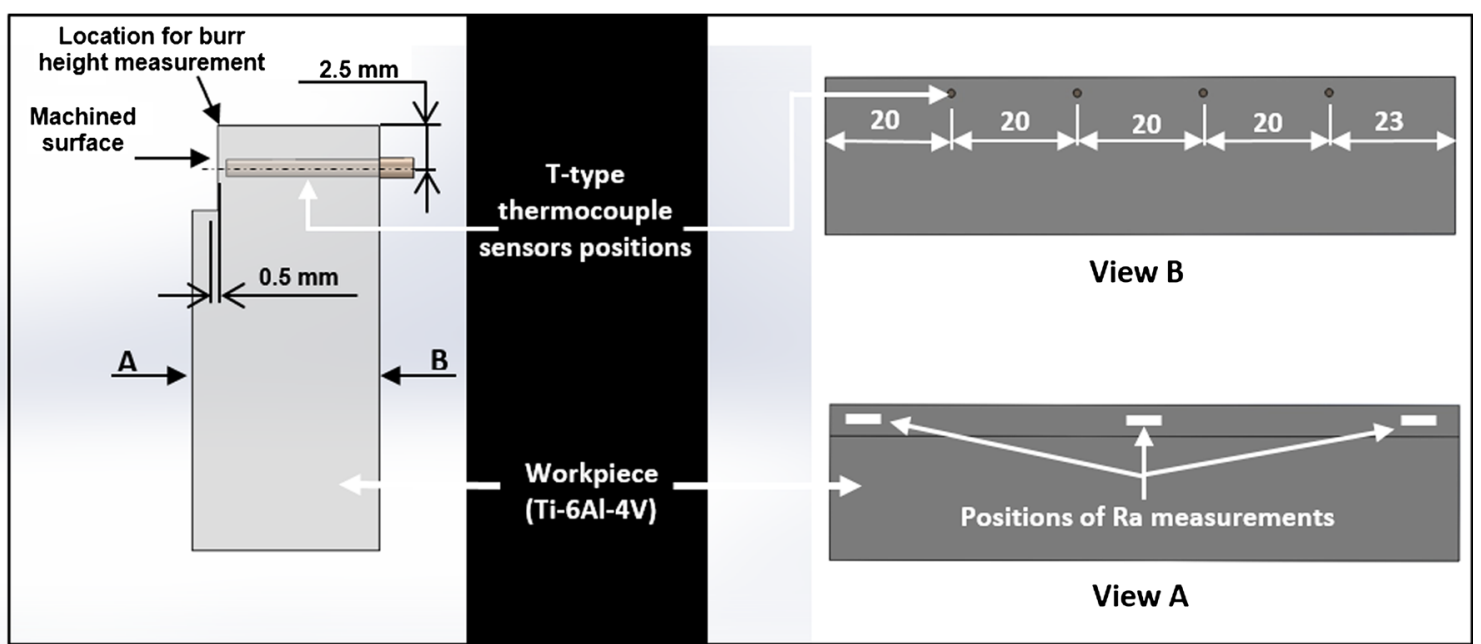

Fig. 7 Positions of $R_{a}$ measurement (view $\mathrm{A}$ ) and thermocouple arrangement (view $\mathrm{B}$ ) for workpiece temperature measurement (dimension in mm)

thus to feed rate. It was also noticed that cutting force increased with higher cutting speed. This agrees with the assumption that more energy is required to remove a higher volume of material and hence higher cutting force [59, 60], although this is in disagreement with the finding that higher cutting speeds may cause material softening, and hence lower cutting forces when machining steel alloys as described by Veiga et al. [36]. Additionally, variations in nozzle positions/ angles and impinging distance had only a limited impact on cutting force.

Workpiece temperature Figure 9 presents the variation of average workpiece temperatures functions of all process variables evaluated in this research. Average workpiece temperature values ranged between 23.5 and $27.5^{\circ} \mathrm{C}$. This is probably because only a small proportion $(\sim 20 \%)$ of the heat generated when cutting titanium is conducted into the workpiece and chip whilst $80 \%$ of the heat are expected to be transferred to the cutting tool [61]. In addition, the impinging fluid jet on targeted heat-affected zones helped to dissipate more than $30 \%$ of the heat generated during the cutting process [35].

Additionally, the decrease in workpiece temperature with higher cutting speeds can be attributed to the increase in cutting fluid flow rate associated with increasing cutting energy (in accordance with increasing working conditions). Increasing the flow rate resulted in improving the cooling capacity of the cutting fluids which assisted to transfer more heat from the workpiece to the cutting fluid, hence a reduction in workpiece temperature. Unexpectedly, the optimal (low) workpiece temperature was recorded at the higher cutting condition and nozzle position at an angle of $15^{\circ}$ in the feed
Fig. 8 Main effects analysis for cutting force

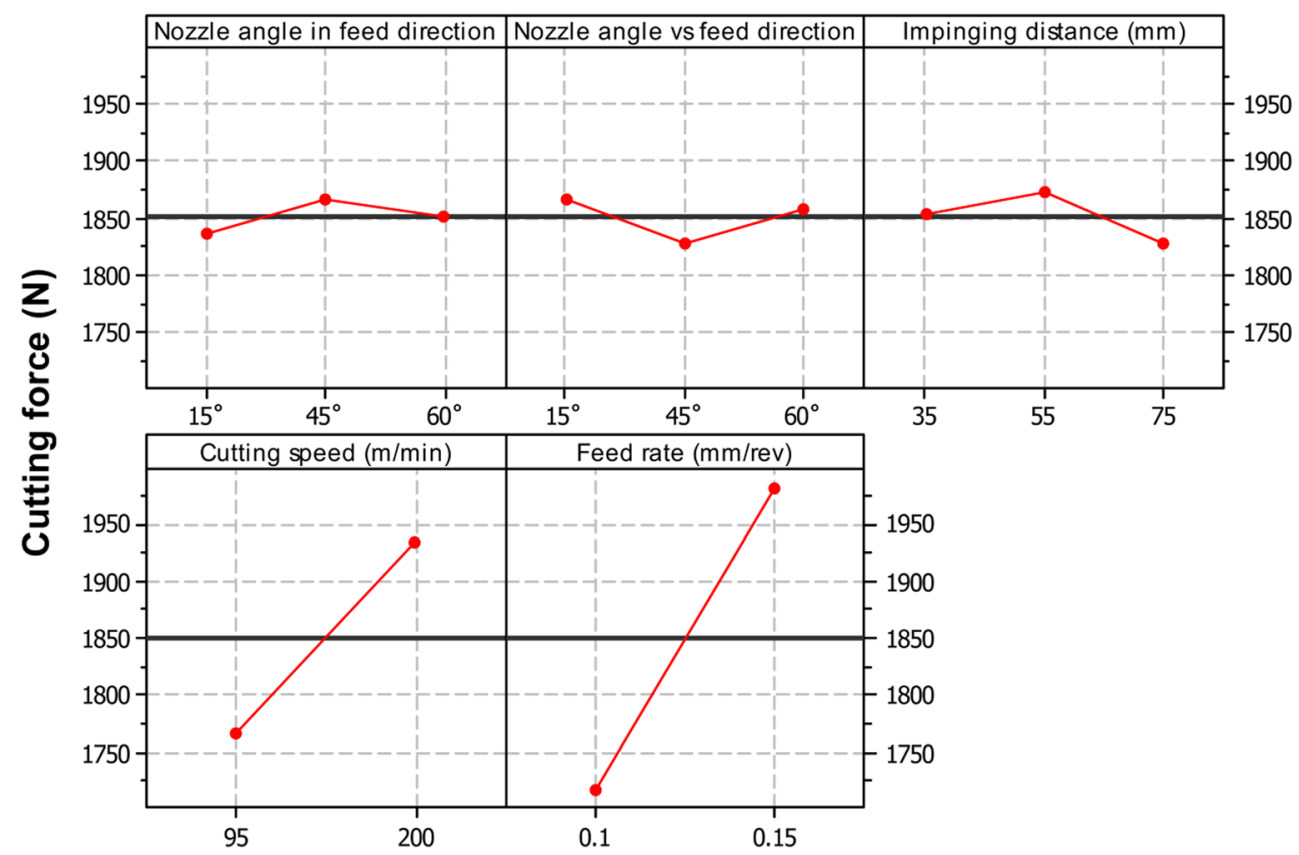


Fig. 9 Main effects analysis for workpiece temperature

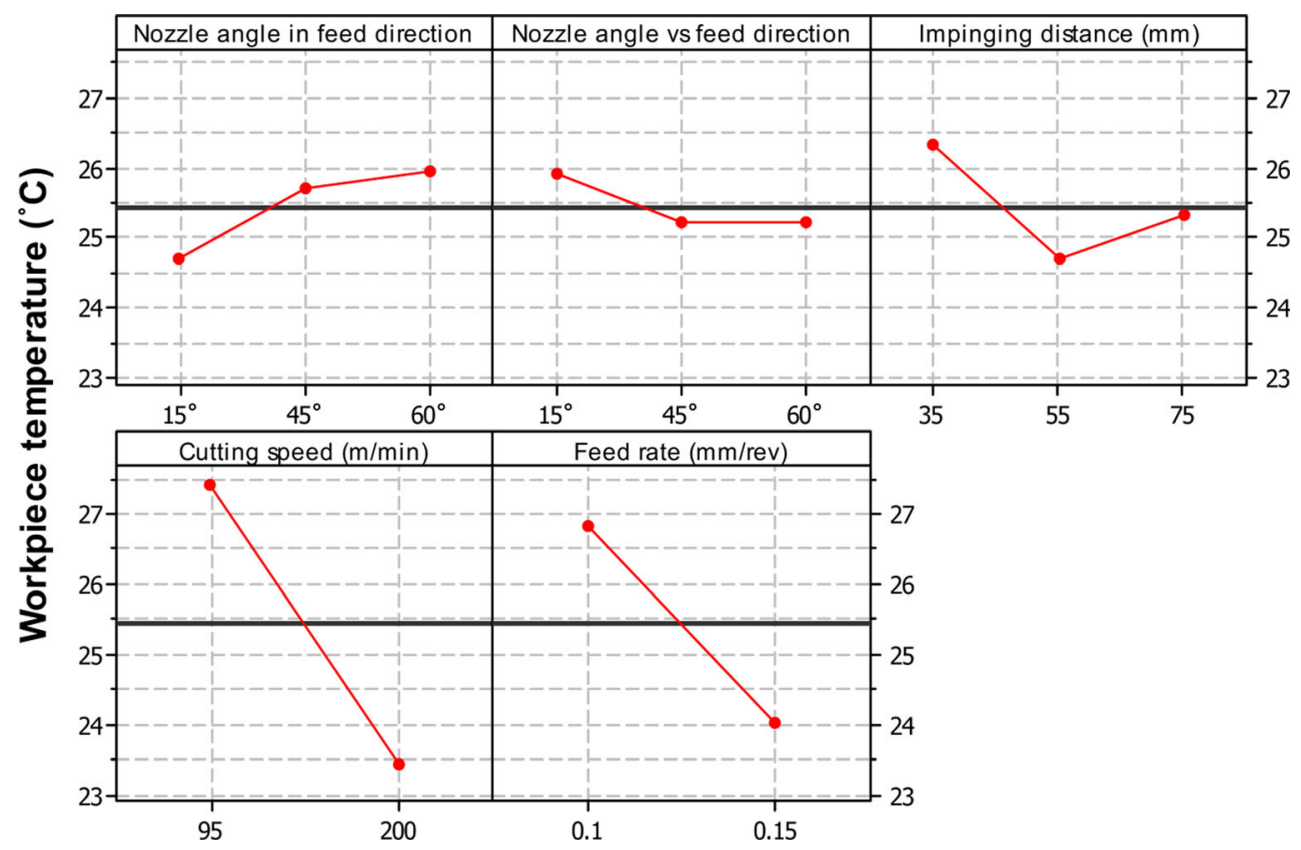

direction and $45^{\circ} / 60^{\circ}$ against feed direction, and an impinging distance of $55 \mathrm{~mm}$. This is due to the increase in the fluid flow rate associated with increasing cutting energy (see Fig. 5), which improved the fluid's ability to transfer more heat from the workpiece to the cutting fluid. Feed rate, impinging distance and nozzle positions, particularly in the feed direction, showed a considerable response to average workpiece temperature.

Tool flank wear Figure 10 demonstrates the effects of control factors on mean values of tool flank wear (VB). A cutting speed of $95 \mathrm{~m} / \mathrm{min}$, feed rate of $0.15 \mathrm{~mm} / \mathrm{rev}$ and nozzle location at $15^{\circ}$ in the feed direction and $45^{\circ}$ against feed direction and an impinging distance of $75 \mathrm{~mm}$ can be selected as the optimal cutting conditions for controlling tool wear. However, the use of the controlled cutting fluid through the developed Cut-list system meant that tool wear increased rapidly with increased cutting speed owing to the rise in heat generated. The heat generated at the tool edge would have softened the insert edge, causing tool flank wear to sequentially increase [62]. Tool flank wear values seem to be independent of feed rate, nozzle position and impinging distance. It can also be
Fig. 10 Main effects analysis of tool flank wear

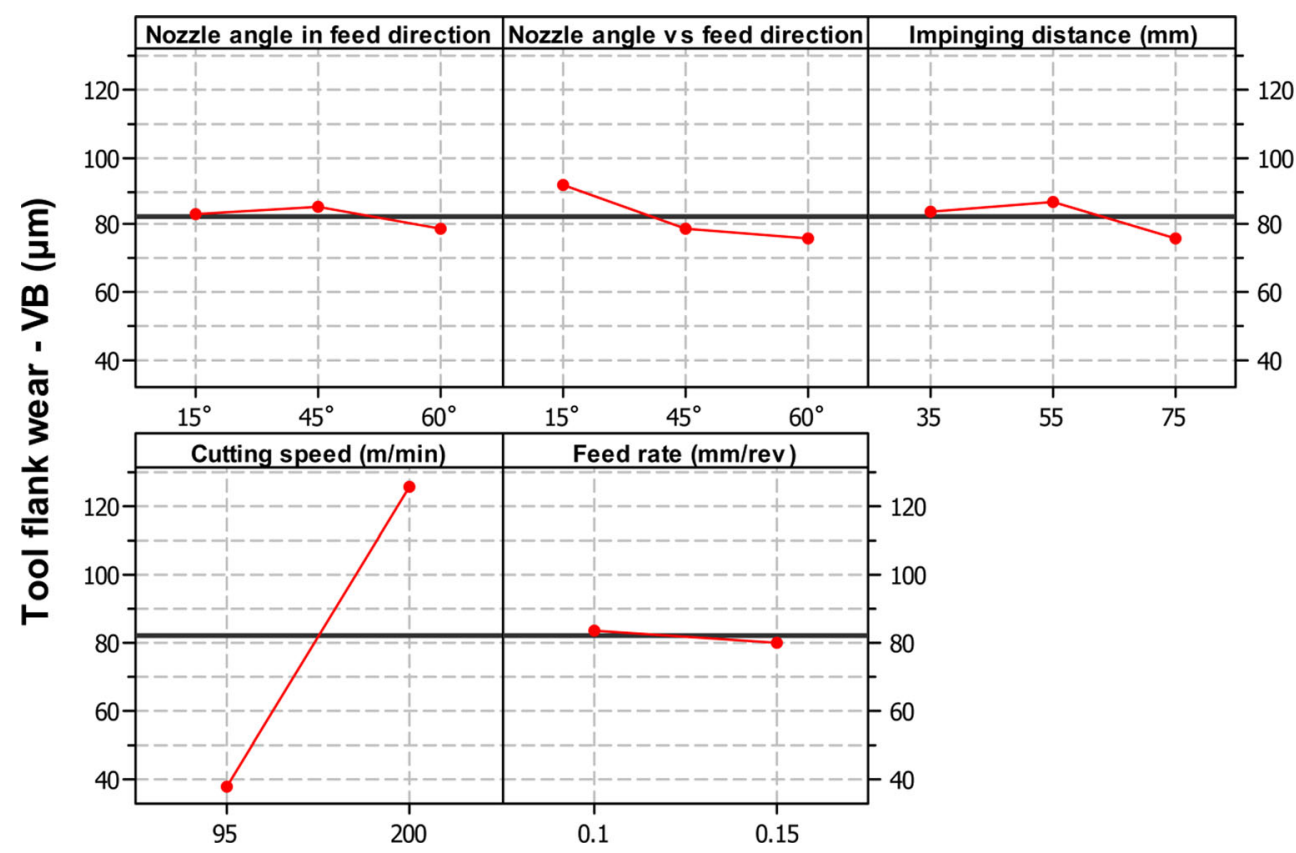


concluded that the traditional understanding that cutting speed is the dominant variable affecting tool wear is still applicable to the Cut-list cutting fluid supply system.

Figure 11 shows an SEM analysis of the used uncoated WC cutting tool edges at various cutting conditions. Wear occurred mainly on the flank face of the cutting tool where uniform abrasive wear was observed at low cutting speed, whereas adhesion has already taken place at higher cutting speed. The adhered substances were examined using EDX, and the presence of titanium element in the adhered materials on the rake face of the tool substrate was found, as shown in Fig. 12. In addition, a few elements such as tungsten (W) and cobalt (Co) from the tool substrate were found in the adhered workpiece material at higher cutting speed, which proves that diffusion took place. The increase in heat generated with increased cutting energy may offer a good atmosphere for the diffusion of tool material atoms across the tool-workpiece interface, and thus, by impairing bonding strength in the tool materials, diffusion wear has occurred [63].
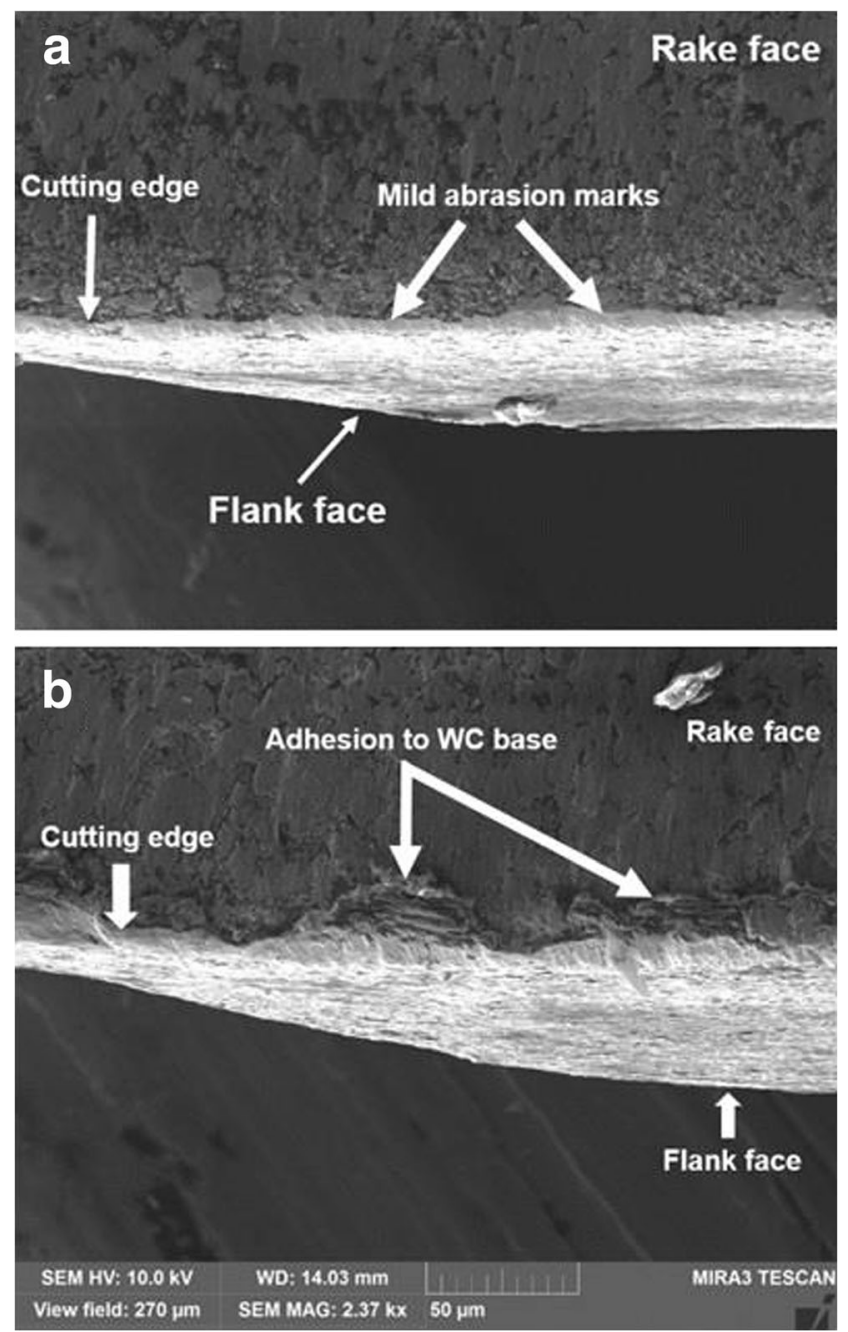

Fig. 11 SEM micrographs of worn tools used to machine Ti-6Al-4V at a $95 \mathrm{~m} / \mathrm{min}, 0.1 \mathrm{~mm} / \mathrm{rev}$, and b $200 \mathrm{~m} / \mathrm{min}, 0.1 \mathrm{~mm} / \mathrm{rev}$
Burr formation Figure 13 presents the variation in average burr height measured at the edge of the machined surface as a function of various process variables assessed in this work. The smallest burr height can be achieved at $200-\mathrm{m} / \mathrm{min}$ cutting speed, $0.15-\mathrm{mm} / \mathrm{rev}$ feed rate, nozzle location at $45^{\circ}$ in the feed direction and $45^{\circ}$ against feed rate direction and an impinging distance of $55 \mathrm{~mm}$. It was observed that burr height tends to decrease rapidly with increased cutting speed and feed rate, and it is relatively sensitive to impinging distance rather than nozzle positions/angles. This is deemed to be due to the impinging distance affecting the fluid velocity [64], which led to maintaining the cutting edge in a sharper condition with less metal seizing. In addition, cutting speed and nozzle angle do not show a significant impact on burr height. Figure 14 shows burrs formed on the milled top surfaces of Ti$6 \mathrm{Al}-4 \mathrm{~V}$ at various cutting conditions.

Surface integrity Average surface roughness $\left(R_{a}\right)$ results at various process and system levels are shown in Fig. 15. Minimum surface roughness was achieved at a cutting speed of $200 \mathrm{~m} / \mathrm{min}$, feed rate of $0.1 \mathrm{~mm} / \mathrm{rev}$, nozzle positions of $45^{\circ}$ and $60^{\circ}$ in feed and against feed direction, respectively, and 75-mm impinging distance. Surface roughness values were found to decrease with rises in cutting speed and decreased feed rates. This can also be attributed to the increase in cutting fluid flow rate associated with increased cutting speed (see Fig. 5). A comparable finding was also reported recently [64] when Xiao et al. investigated the end-milling of Ti-6Al$4 \mathrm{~V}$ under MQL at four different fluid supply rates (2, 6, 10 and $14 \mathrm{ml} / \mathrm{h}$ ). However, the effect of feed rate on mean values of $R_{a}$ seems much higher than that of cutting speed. This is likely to be due to the theoretical surface roughness being directly proportional to the square of the feed per revolution. In the same vein, decreased feed rate possibly gave the cutting fluid enough time to carry away the heat from the machining zone, and led to a low material removal rate and the accumulation of chip in the tool-workpiece zones, which resulted in an improved surface finish. It was noted that the major effective parameter to reduce $R_{a}$ is the feed rate, whilst cutting speed and impinging distance showed less noticeable effects on $R_{a}$ values. Additionally, SEM images for titanium samples before and after the machining trials confirmed that no major changes in the micro-structure as well as no signs for surface or subsurface damage are seen in Fig. 16.

Nozzle position effect Workpiece temperature was found to be influenced by nozzle position/angle, in particular in the feed direction, as can be seen in Fig. 9. Seemingly, locating nozzle at $15^{\circ}$ in the feed direction helped to create efficient fluid trapping between the tool and workpiece surfaces which, in turn, led to improving the accessibility of cutting fluid into the machining zone to perform both cooling and lubrication functions adequately. A similar phenomenon was observed in 
Fig. 12 EDX analysis performed on the rake face of the insert at cutting speed of $200 \mathrm{~m} / \mathrm{min}$ and feed rate of $0.1 \mathrm{~mm} / \mathrm{rev}$

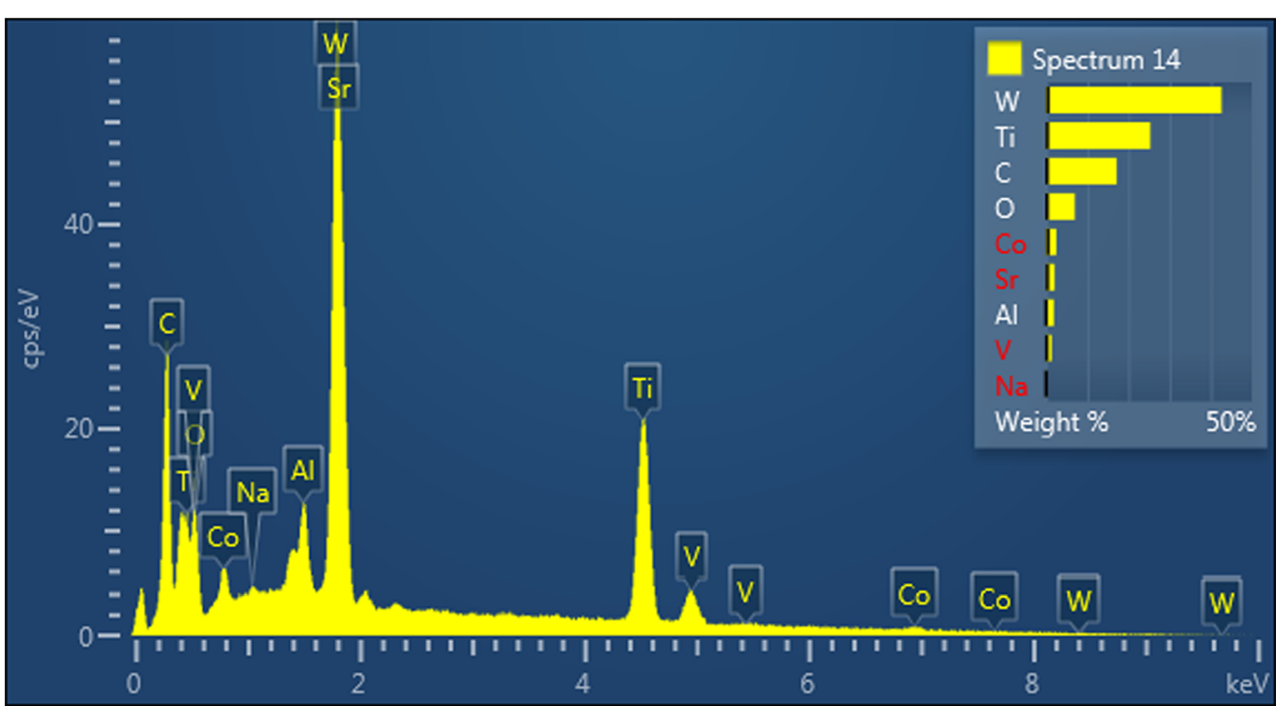

another study [65], where it was found that shifting the nozzle from a $45^{\circ}$ angle to an acute angle of $12.5^{\circ}$ in the feed direction when end-milling H13 steel under MQL assisted in increasing the amount of cutting fluid reaching the machining zone. Additionally, the proximity of the nozzle positioned at an angle of $15^{\circ}$ from the tool-workpiece contact point contributed in minimising the fluid particle dispersion caused by tool rotation, which allowed them to adhere to the tool and workpiece surfaces effectively and to persist in working as a lubricant in the machining zone. Conversely, at the nozzle positions of $45^{\circ}$ or $60^{\circ}$, more cutting fluid particles are driven away from the tool surface whilst the cutting tool rotates in a cyclic loop process [66]. In addition, nozzle placement at an angle of $45^{\circ}$ or $60^{\circ}$ against feed direction tends to offer enough space to assist in chip evacuation and this helped to minimise the interference between the impinging jet and the removed chip, which led to better lubricating and cooling ability and consequently improved machined surfaces.

Impinging distance effect According to Figs. 9, 13 and 15, impinging distance had a noticeable impact on workpiece temperature, burr formation and average surface roughness. According to Bernoulli's equation (Eq. 4) [66], the hydraulic head $(h)$ (where in this case, the impinging distance is equal to the hydraulic head) has an effect on jet velocity, and this consequently affected fluid penetration efficiency. The cutting fluid jet velocity $\left(V_{j}\right)$ increases as the impinging distance decreases. However, too short impinging distance has a negative effect on the cutting fluid droplets owing to their high levels of rebounding from the workpiece and cutter surfaces [66].
Fig. 13 Main effects analysis for average burr height

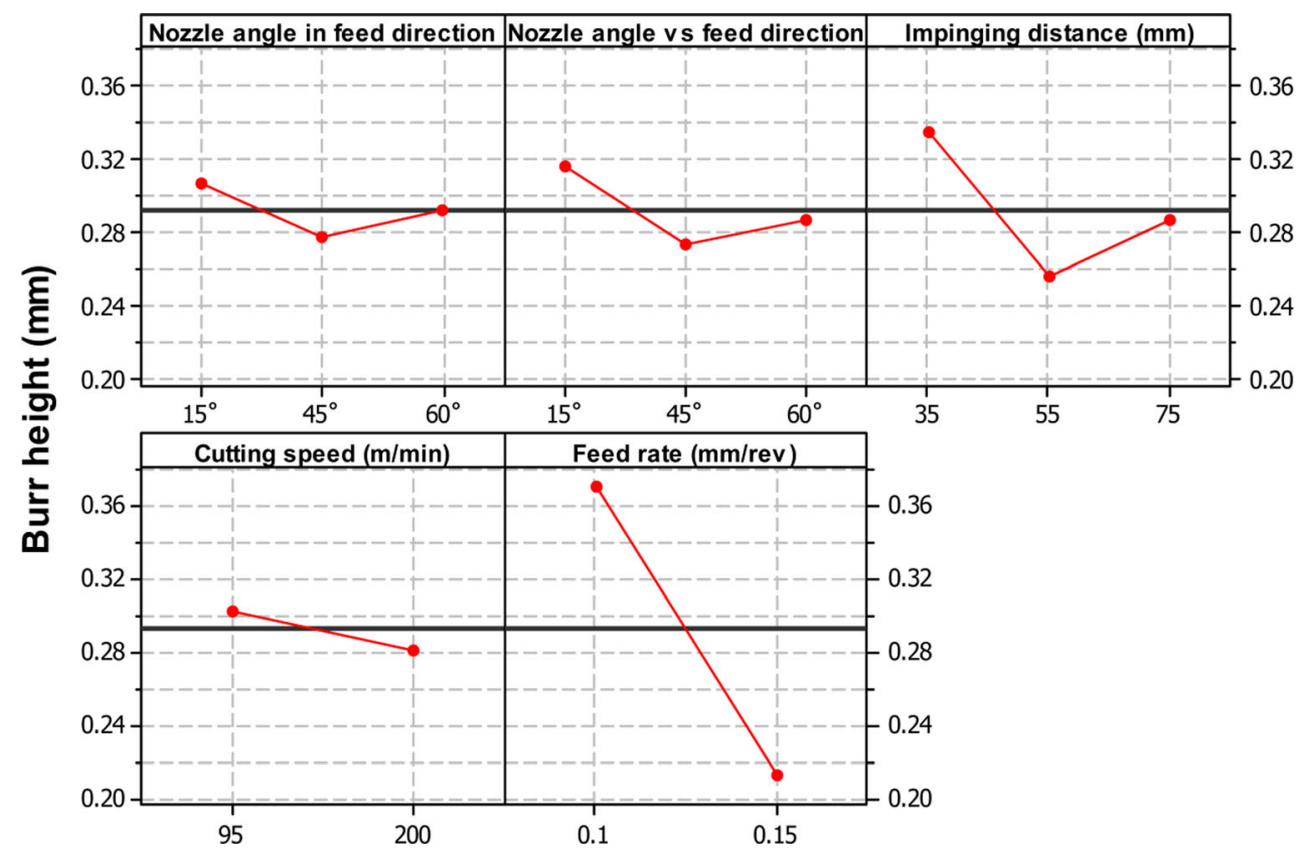


Fig. 14 Images for the burrs formed on milled top surfaces at different cutting conditions. a $95 \mathrm{~m} / \mathrm{min} \times 0.1 \mathrm{~m} / \mathrm{rev}$. b $95 \mathrm{~m} /$ $\min \times 0.15 \mathrm{~mm} / \mathrm{rev}$. c $200 \mathrm{~m} /$ $\min \times 0.1 \mathrm{~mm} / \mathrm{rev}$. d $200 \mathrm{~m} /$ $\min \times 0.15 \mathrm{~mm} / \mathrm{rev}$
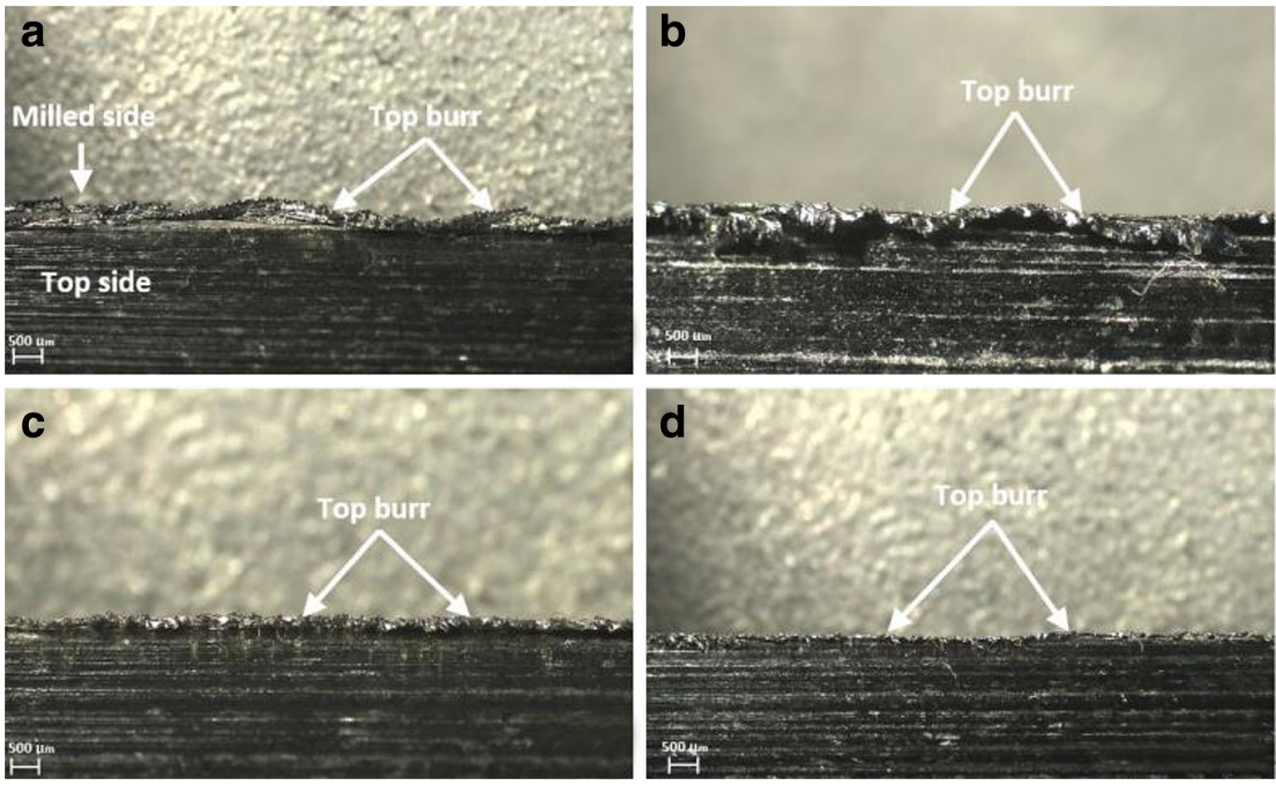

Therefore, impinging distance should be controlled at an optimal level, as the impact of shorter impinging distance would be to conspicuously affect the workpiece temperature, burr formation and average surface roughness. Since the optimal impinging distances obtained for controlling the aforementioned responses were $55 / 75 \mathrm{~mm}$, they tend to have a combined action by improving the fluid penetration ability with less fluid dispersion and spring-back effect, which in turn assisted the cutting fluid droplets to adhere firmly to the workpiece and cutter surfaces.

$\frac{1}{2} \rho V_{j}^{2}+\rho \mathrm{g} h+p=$ constant

\subsection{Performance comparison with a conventional flood system (part II)}

Data collected using the new system was compared with a conventional (uncontrolled) flood supply system. The best results were considered (i.e. amongst every 27 tests conducted at the same cutting speed and feed rate). In general, the new system (Cut-list) showed better performance compared to the conventional system although the $42 \%$ reduction in cutting fluid consumption achieved by the Cut-list. Cutting force ranged between $1600-1903 \mathrm{~N}$ and $1340-1879 \mathrm{~N}$ for the conventional and new system, respectively. This provided a
Fig. 15 Main effects analysis for surface roughness

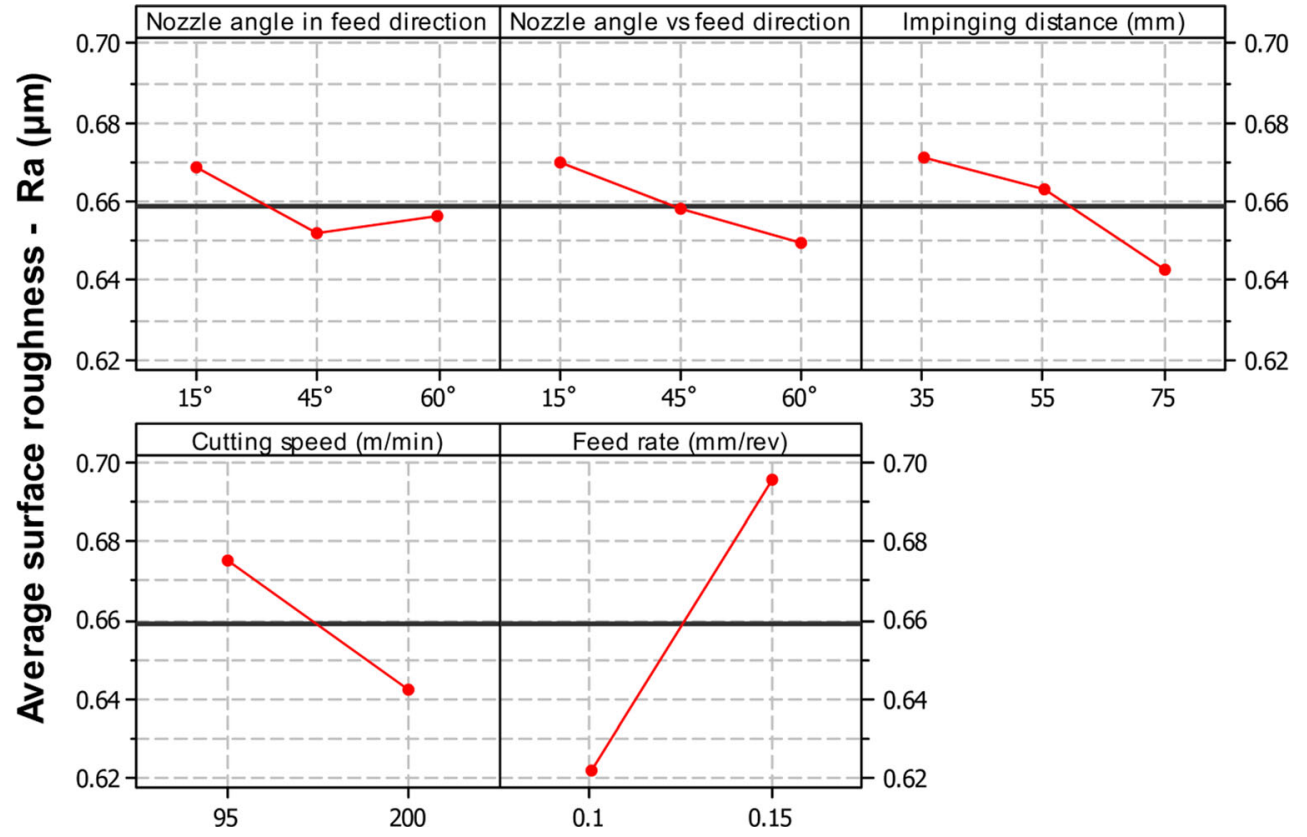



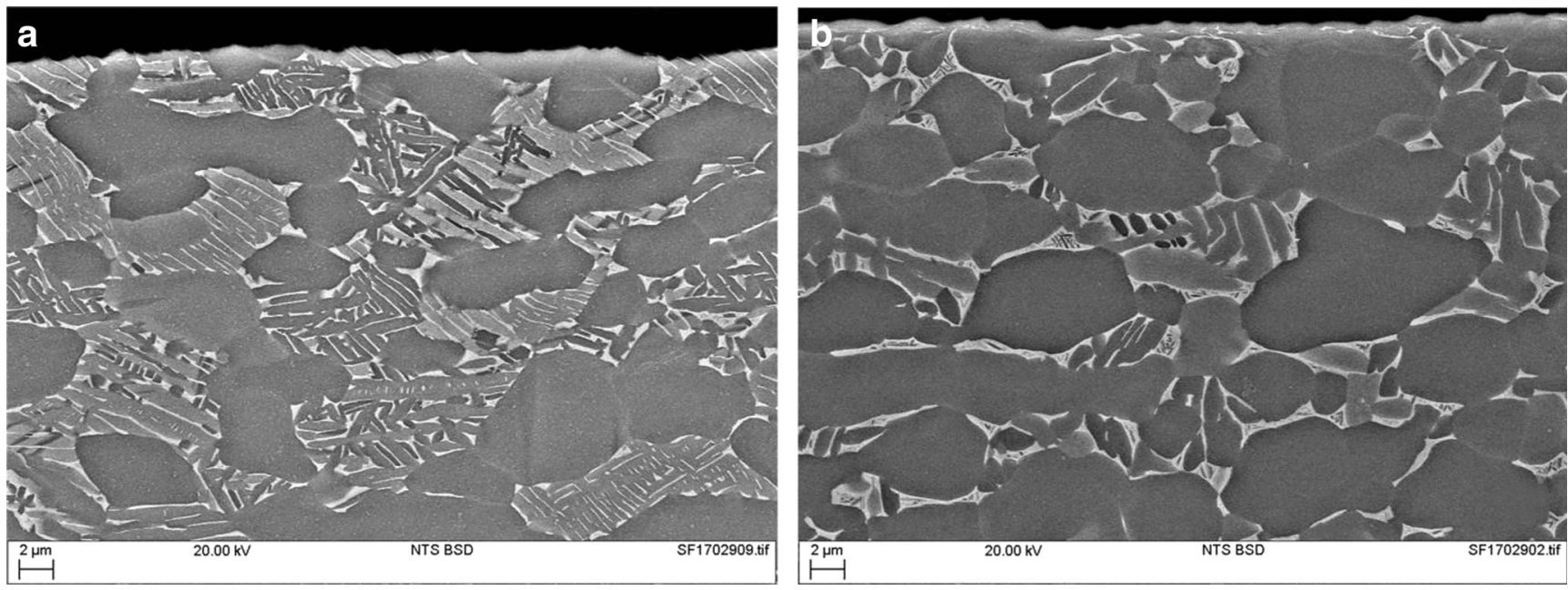

Fig. 16 SEM images for the micro-structure of a as received annealed Ti-6Al-4V and $\mathbf{b}$ machined surface using the new Cut-list at 200-m/min cutting speed and $0.15-\mathrm{mm} / \mathrm{rev}$ feed rate

reduction of $16 \%$ in cutting force, particularly at a low feed rate $(0.1 \mathrm{~mm} / \mathrm{rev})$ owing to the good penetrability of the new system, which led to forming the boundary of the oil film between the workpiece and cutting tool surfaces, resulting in reducing contact pressure. Additionally, a significant reduction in tool wear up to $46.77 \%$ was achieved at the higher cutting condition (i.e. $200 \mathrm{~m} / \mathrm{min}$ and $0.15 \mathrm{~mm} / \mathrm{rev}$ ) utilising the Cut-list. Impinging the cutting fluid in both directions (with and against feed) helped to penetrate the fluid effectively into machining zone and cool the tool insert at the end of the cyclic process. In terms of burr formation, burr height ranged between $0.11-0.41 \mathrm{~mm}$ and $0.1-0.17 \mathrm{~mm}$ for the conventional and new system, respectively. This afforded a significant reduction up to $31.70 \%$ in burr height, particularly at higher cutting speed (i.e. $200 \mathrm{~m} / \mathrm{min}$ ) owing to the high velocity of the jet (i.e. $10 \mathrm{~m} / \mathrm{s}$ ). In addition, no substantial differences were found between systems in workpiece temperature results (maximum of $1.5^{\circ} \mathrm{C}$ ), whilst average surface roughness $\left(R_{a}\right)$ values were relatively smaller with the use of the new system.

\section{Conclusions}

This paper presents a comprehensive experimental evaluation of a new cutting fluid supply system (Cut-list) when machining Ti-6Al-4V using vegetable oil-based cutting fluid. In general, the new system (Cut-list) was found to perform favourably as compared to the conventional system. It significantly reduced cutting fluid consumption up to $42 \%$, cutting force by $16.41 \%$, tool flank wear by $46.77 \%$ and burr formation by $31.70 \%$. However, no notable discrepancy in workpiece temperature values was found between the two systems [67]. Feed rate was the dominant factor affecting mean cutting force, burr formation and surface roughness, whilst cutting speed has the greatest impact on workpiece temperature and tool flank wear. The cooling performance of the new system is relatively sensitive to nozzle positions and impinging distance with respect to workpiece temperature, burr formation and surface roughness $\left(R_{a}\right)$. Lastly, it can be concluded that coherent round nozzle can be used effectively to replace conventional sloped nozzle in milling operations.

Funding This work is sponsored by the Libyan government and technically supported by the Mechanical and Construction Engineering Department, Northumbria University at Newcastle, UK.

Open Access This article is distributed under the terms of the Creative Commons Attribution 4.0 International License (http:// creativecommons.org/licenses/by/4.0/), which permits unrestricted use, distribution, and reproduction in any medium, provided you give appropriate credit to the original author(s) and the source, provide a link to the Creative Commons license, and indicate if changes were made.

\section{References}

1. El Baradie MA (1996) Cutting fluids: part I. Characterisation. J Mater Process Technol 56(1-4):786-797

2. Byers JP (2006) Metalworking fluids, 2nd edn. CRC Press, Hoboken, pp p57-p104

3. Astakhov VP Cutting fluids (coolants) and their application in deephole machining. Online URL: http://viktorastakhov.tripod.com/DH/ coolant. pdf] accessed on October, 2001. 23(2015): pp. 1-17

4. Priarone PC et al (2014) Milling and turning of titanium aluminides by using minimum quantity lubrication. Procedia CIRP 24(0):62-67

5. Shokrani A, Dhokia V, Newman ST (2012) Environmentally conscious machining of difficult-to-machine materials with regard to cutting fluids. Int J Mach Tools Manuf 57:83-101

6. Kalpakjian, Schmid SR (2001) Manufacturing engineering and technology, 4th edn. Newjersy, Prentice Hall

7. Dixit U, Sarma D, Davim JP (2012) Machining with minimal cutting fluid, in Environmentally Friendly Machining. Springer. p. 9-17

8. Koen D (2011) Investigation of novel cooling methods to enhance aerospace component manufacturing practices, in Faculty of 
Engineering Department of Industrial Engineering. Stellenbosch University: Stellenbosch University

9. Bennett E (1983) Water based cutting fluids and human health. Tribol Int 16(3):133-136

10. Soković M, Mijanović K (2001) Ecological aspects of the cutting fluids and its influence on quantifiable parameters of the cutting processes. J Mater Process Technol 109(1-2):181-189

11. Osama $\mathrm{M}$ et al (2017) Recent developments and performance review of metal working fluids. Tribol Int 114:389-401

12. Sharma AK, Tiwari AK, Dixit AR (2016) Effects of minimum quantity lubrication (MQL) in machining processes using conventional and nanofluid based cutting fluids: a comprehensive review. J Clean Prod 127:1-18

13. Maruda RW et al (2017) Tool wear characterizations in finish turning of AISI 1045 carbon steel for MQCL conditions. Wear 372373:54-67

14. Maruda RW et al (2017) Structural and microhardness changes after turning of the AISI 1045 steel for minimum quantity cooling lubrication. J Mater Eng Perform 26(1):431-438

15. Revuru RS et al (2017) Application of cutting fluids in machining of titanium alloys - a review. Int J Adv Manuf Technol 91(5-8): 2477-2498

16. Sharif MN, Pervaiz S, Deiab I (2017) Potential of alternative lubrication strategies for metal cutting processes: a review. Int J Adv Manuf Technol 89(5):2447-2479

17. Debnath S, Reddy MM, Yi QS (2014) Environmental friendly cutting fluids and cooling techniques in machining: a review. J Clean Prod 83:33-47

18. Sharma VS, Dogra M, Suri NM (2009) Cooling techniques for improved productivity in turning. Int J Mach Tools Manuf 49(6): $435-453$

19. Jayal AD, Balaji AK (2009) Effects of cutting fluid application on tool wear in machining: interactions with tool-coatings and tool surface features. Wear 267(9-10): 1723-1730

20. Babic D, Murray DB, Torrance AA (2005) Mist jet cooling of grinding processes. Int J Mach Tools Manuf 45(10):1171-1177

21. Çakır O, Kıyak M, Altan E (2004) Comparison of gases applications to wet and dry cuttings in turning. J Mater Process Technol 153-154:35-41

22. Sun $\mathbf{J}$ et al (2006) Effects of coolant supply methods and cutting conditions on tool life in end milling titanium alloy. Mach Sci Technol 10(3):355-370

23. Benedicto E, Carou D, Rubio EM (2017) Technical, economic and environmental review of the lubrication/cooling systems used in machining processes. Procedia Eng 184:99-116

24. de Oliveira, JFG (2008) Vegetable based cutting fluid - an environmental alternative to grinding process, In 15th CIRP International Conference on Life Cycle Engineering. p. 5

25. Belluco W, De Chiffre L (2004) Performance evaluation of vegetable-based oils in drilling austenitic stainless steel. J Mater Process Technol 148(2):171-176. https://doi.org/10.1016/S09240136(03)00679-4

26. Lawal SA, Choudhury IA, Nukman Y (2012) Application of vegetable oil-based metalworking fluids in machining ferrous metalsa review. Int J Mach Tools Manuf 52(1):1-12

27. Kuram E, Ozcelik B, Demirbas E (2013) Environmentally friendly machining: vegetable based cutting fluids, in Green Manufacturing Processes and Systems. Springer. pp. 23-47

28. Kumar Gajrani K, Ravi Sankar M (2017) Past and current status of eco-friendly vegetable oil based metal cutting fluids. Materials Today: Proceedings 4 (2, Part A):3786-3795. https://doi.org/10. 1016/j.matpr.2017.02.275

29. Siniawski MT et al (2007) Influence of fatty acid composition on the tribological performance of two vegetable-based lubricants. J Synth Lubr 24(2):101-110
30. Nandy AK, Gowrishankar MC, Paul S (2009) Some studies on high-pressure cooling in turning of Ti-6Al-4V. Int J Mach Tools Manuf 49(2):182-198

31. Yassin A, Teo CY (2014) Effect of pressure and nozzle angle of minimal quantity lubrication on cutting temperature and tool wear in turning. Appl Mech Mater, (695)

32. Wang C-D et al (2014) Tool wear performance in face milling Inconel 182 using minimum quantity lubrication with different nozzle positions. Int J Precis Eng Manuf 15(3):557-565. https://doi. org/10.1007/s12541-014-03714

33. Tawakoli T, Hadad MJ, Sadeghi MH (2010) Influence of oil mist parameters on minimum quantity lubrication-MQL grinding process. Int J Mach Tools Manuf 50(6):521-531

34. Ezugwu J (2003) Bonney, and Y. Yamane, An overview of the machinability of aeroengine alloys. J Mater Process Technol 134(2):233-253

35. Pramanik A (2014) Problems and solutions in machining of titanium alloys. Int J Adv Manuf Technol 70(5-8):919-928

36. Veiga C, Davim J, Loureiro A (2013) Review on machinability of titanium alloys: the process perspective. Rev Adv Mater Sci 34(2): 148-164

37. Cheng K (2009) Machining dynamic, fundamental, application and practices, 1st edn. Springer-Verlag, London

38. Ítalo Sette Antonialli A, Eduardo Diniz A, Pederiva R (2010) Vibration analysis of cutting force in titanium alloy milling. Int $\mathrm{J}$ Mach Tools Manuf 50(1):65-74

39. Fwamba JC et al (2017) Experimental investigation of chatter trends in titanium end milling. Procedia Manuf 7(Supplement C): 163-171

40. Patil A, Sushil I (2015) Machining challenges in Ti-6Al-4V-a review. 5:6-23

41. Gok A, Gologlu C, Demirci HI (2013) Cutting parameter and tool path style effects on cutting force and tool deflection in machining of convex and concave inclined surfaces. Int J Adv Manuf Technol 69(5-8):1063-1078

42. Wojciechowski $\mathrm{S}$ et al (2016) Investigation on the edge forces in ball end milling of inclined surfaces. Int $\mathrm{J}$ Mech $\mathrm{Sci}$ 119(Supplement C):360-369

43. Allwood JM et al (2016) Manufacturing at double the speed. J Mater Process Technol 229:729-757

44. Kennametal, Titanium machining guide. 2016, Kennametal: www. kennametal.com/content/dam/kennametal/kennametal/common/ Resources/Catalogs-Literature/Industry\%20Solutions/Titanium material machining guide Aerospace.pdf

45. Cimcool, Machining titanium. 2017, Cimcool: http://www. cimcool.com/wp-content/uploads/tech-reports/machiningtitanium. pdf, USA

46. Webster JA (2007) Improving surface integrity and economics of grinding by optimum coolant application, with consideration of abrasive tool and process regime. Proc Inst Mech Eng B J Eng Manuf 221(12):1665-1675

47. Rowe WB, Hitchnier M (2007) Handbook of machining with grinding, 2nd edn. CRC Press, USA

48. Liu J et al (2014) Prediction of heat transfer process in helical milling. Int J Adv Manuf Technol 72(5-8):693-705

49. Grzesik W (2017) Chapter nine-heat in metal cutting, in Advanced Machining Processes of Metallic Materials (Second Edition). Elsevier. p. 163-182

50. Liu J, Ren C, Qin X, Li H (2014) Prediction of heat transfer process in helical milling. The International Journal of Advanced Manufacturing Technology 72 (5-8):693-705

51. Karaguzel U, Bakkal M, Budak E (2016) Modeling and measurement of cutting temperatures in milling. Procedia CIRP 46:173-176

52. Cui X, Guo J (2017) Effects of cutting parameters on tool temperatures in intermittent turning with the formation of serrated chip considered. Appl Therm Eng 110:1220-1229 
53. Altintas Y (2012) Manufacturing automation: metal cutting mechanics, machine tool vibrations, and $\mathrm{CNC}$ design. Cambridge university press

54. Metzger JL (1986) Superabrasive Grinding. Butterworths, London, UK. p. $134-137$

55. Coromant AS (1994) Modern metal cutting — a practical handbook, 1st edn. AB Sandvik Coromant, Sandviken, pp X-21

56. Boothroyd G, Knight WA (2005) Fundamental of machining and machine tool, 3rd edn. CRC Press Francis \& Taylor, USA

57. Webster (2008) Coolant calculus, In Cutting tool engineering. Cutting Tool Engineering: USA. p. 8

58. Luchesi VM, Coelho RT (2012) Experimental investigations of heat transfer coefficients of cutting fluids in metal cutting processes: analysis of workpiece phenomena in a given case study. Proc Inst Mech Eng B J Eng Manuf: p. 0954405412442459

59. Park K-H et al (2014) Eco-friendly face milling of titanium alloy. Int J Precis Eng Manuf 15(6):1159-1164

60. Krishnaraj V et al (2014) A study on high speed end milling of titanium alloy. Procedia Eng 97:251-257

61. Ezugwu EO et al (2017) Overview of the machining of titanium alloys, in Reference Module in Earth Systems and Environmental Sciences. Elsevier
62. Thamizhmanii S, Rosli SH (2009) A study of minimum quantity lubrication on Inconel 718 steel. World academy of materails and manufacturing engineering. Arch Mater Sci Eng 39(1):38-44

63. Astakhov VP (2004) The assessment of cutting tool wear. Int J Mach Tools Manuf 44(6):637-647

64. Cai XJ et al (2012) An experimental investigation on effects of minimum quantity lubrication oil supply rate in high-speed end milling of Ti-6Al-4V. Proc Inst Mech Eng B J Eng Manuf: p. 0954405412458492

65. Mulyadi IH (2013) Improving the performance of minimum quantity lubrication in high speed milling and environmental performance analysis. In: School of Mechanical, Aerospace and Civil Engineering. University of Manchester, Manchester, p 204

66. Liu Z et al (2011) Investigation of cutting force and temperature of end-milling Ti-6Al-4V with different minimum quantity lubrication (MQL) parameters. Proceed Inst Mech Eng Part B: J Eng Manuf 225(8):1273-1279

67. Gariani S et al (2017) Evaluation of a novel controlled cutting fluid impinging supply system when machining titanium alloys. Appl Sci 7(6):560 